\title{
Fuera del mundo, dentro del arte. Correspondencias entre Baudelaire y Ortega
}

\author{
Constanza Nieto Yusta \\ UNED \\ cnietoy@geo.uned.es
}

RESUMEN: El pensamiento de Ortega y Gasset, entendido como un proyecto de conciliación entre tradición y modernidad, muestra la influencia de una de las principales figuras en la gestación de la modernidad literaria y artística: Charles Baudelaire. En este artículo se analizarán los puntos en común entre ambos, resaltando cómo Baudelaire y Ortega comparten la dialéctica entre «lo nuevo» y «lo viejo» y cómo ambos encuentran en el arte el camino para su resolución.

PALABRAS CLAVE: Ortega y Gasset, Charles Baudelaire, Modernidad, Arte, Estética.

\section{Out of the World, Inside the Arts. Correspondence between Baudelaire and Ortega}

ABSTRACT: Ortega y Gasset's thought, considered as an attempt to reconcile tradition and modernity, reveals the influence of one of the leading figures in the theories of literary and aesthetic modernism: Charles Baudelaire. This paper will discuss the common ground between Ortega and Baudelaire: the Dialectic of New and Old and the vindication of Art as the major solution for this struggle.

KEYWORDS: Ortega y Gasset, Charles Baudelaire, Modernism, Art, Aesthetics.

Recibido: 14 de abril de 2016 / Aceptado: 23 de junio de 2016.

En los escritos de Ortega y Gasset, la influencia de Baudelaire aparece de dos modos y en dos periodos claramente diferenciados: de forma velada a lo largo de los primeros escritos, esto es, como una lectura que el propio Ortega aplicó a algunas de sus reflexiones sobre la modernidad y su dialéctica temporal entre el presente y el pasado; y de un modo evidente ya a partir de la década de los años veinte, es decir, como cita explícita. No creemos que estos dos momentos sean casuales: la reconciliación progresiva que Ortega fue sintiendo hacia Francia y la necesaria incorporación del arte en su sistema de pensamiento son, a todas luces, las causas de esta visibilidad cada vez mayor de la influencia del poeta francés en sus escritos. Y, puesto que el nombre de Baudelaire aparece precisamente en dos de las reflexiones más relevantes del filósofo madrileño en lo que al arte se refiere -el Brindis en un banquete en su honor en «Pombo» (1922) y La deshumanización del arte (1925)'-, un análisis de esta influencia parece más que necesaria. Deteniéndonos en la impronta que Baudelaire pudo dejar en el pensamiento de Ortega abordaremos la dialéctica de «lo viejo» y de "lo nuevo" y el papel determinante del arte en su resolución.

En tanto hombre «a la altura de los tiempos», Ortega tuvo que conocer el pensamiento de Baudelaire. Desde 1880, año en el que España inició la traducción de las principales obras de Baudelaire, la influencia del poeta francés en nuestro país fue in crescendo (Hambroock, 2012). Las principales figuras de la Generación del 98 acogieron en sus escritos la idea de la modernidad como «tiempo intemporal»: Azorín declaró a Baudelaire el «padre de la poesía decadente moderna» en 1904 y construyó su noción de la Historia a partir del tiempo como Eternidad presente²; y Valle-Inclán reflexionó sobre la eternidad

NIETO YUSTA, Constanza: «Fuera del mundo, dentro del arte. Correspondencias entre Baudelaire y Ortega", Boletín de Arte, n. ${ }^{\circ} 37$, Departamento de Historia del Arte, Universidad de Málaga, 2016, pp. 149-156, ISSN: 0211-8483. 
del momento efímero en La lámpara maravillosa (Valle-Inclán, 1916: 31). Tal y como ha demostrado Glyn Hambroock en varios estudios (1995a; 1995b) el modernismo literario español también acogió la influencia del autor de Las flores del mal. Incluso el mismo Ramón Gómez de la Serna le dedicó una de sus Efigies, «El desgarrado Baudelaire». De modo que si Ortega y Gasset quería construir un sistema coherente con la sensibilidad de su tiempo, no podía dejar de lado en su pensamiento a Charles Baudelaire.

La comunión que Ortega pudo experimentar con el pensamiento del poeta francés puede ser más profunda de lo que se ha apuntado hasta el momento. Tal y como ha mostrado Jean Clair en su ya clásico ensayo La responsabilidad del artista, la formulación de la modernidad realizada por Baudelaire ha de tomarse en su justa medida, a saber: como un grito de angustia que buscaba aproximarse más al antiguo sentido de «lo moderno»-aquello que se adecúa al modo, al momento- que a su mera contraposición a «lo antiguo» ${ }^{3}$. Al igual que Clair, nosotros entendemos que es especialmente relevante señalar el papel de este elemento «reaccionario» en la formulación de la modernidad de Baudelaire pues en la reivindicación de lo eterno junto a lo temporal es donde se encuentran las claves para comprender la continuidad de las formulaciones religiosas de la modernidad, la proclamación del retorno al orden y el fatal desenlace en la historia europea en los totalitarismos.

Baudelaire, tal y como ha mostrado Paul Lidsky, fue uno de los muchos escritores que reaccionaron con complacencia ante la represión de la Comuna de París ${ }^{4}$. El sentimiento aristocrático que imbuía a los intelectuales y artistas decimonónicos también alcanzó a Baudelaire: pese a zambullirse en la multitud, a su coqueteo con los bajos fondos y a su vida de pobreza y miseria, el dandy Baudelaire se regía por criterios elitistas, despreciando al vulgo y considerando necesario el papel de la aristocracia en la gestión y desarrollo de la cultura y del arte. De ahí que algunos autores como Antoine Compagnon prefieran considerar a Baudelaire como uno de los grandes «antimodernos» que poblaron el panorama intelectual desde el siglo XIX hasta finales del siglo del XX: junto a figuras como Balzac, Chateaubriand, Léon Bloy, Paul Bourget o Ferdinand Brunetière, Baudelaire formó parte del grupo de «los modernos en dificultades en los tiempos modernos, el modernismo o la modernidad, o los modernos que lo fueron a regañadientes, modernos desarraigados, o incluso modernos intempestivos» (Compagnon, 2007: 11). Y Ortega y Gasset, el filósofo que se declaró «nada moderno y muy siglo $X X$ », responde a la perfección a la categoría de «antimoderno» señalada por Compganon. El «antimoderno» se caracterizaría por su resistencia ambivalente ante «lo nuevo», sólo aceptable en relación con un pasado hacia el que se siente una cierta nostalgia; por ocupar un lugar de tránsito entre el pasado y el presente, entre «lo viejo» y «lo nuevo»: en definitiva, por ser el puente entre la tradición y la modernidad (Compagnon, 2007: 15). ¿Cómo no iba Ortega a comulgar con un Baudelaire entendido desde estos parámetros?

Es en sus cartas de juventud donde Ortega ya dejó aflorar la conexión de sus ideas con Baudelaire. El 27 de febrero de 1905, Ortega escribía a su padre:

París me ha maravillado, deslumbra y pone los nervios en tensión prodigiosa. He visto bastantes cosas y sobre todo he callejeado hasta reventarme [...].

Hay, para el que llega de las poblaciones españolas a París, una impresión terrible que no creo se haya descrito: la ciudad plana. En Madrid y no digamos en Toledo, Málaga, etc., como las calles suben y bajan y hay edificios a toda clase de alturas, desde cualquier lugar en que se coloque uno ve partes muy lejanas de la población, esquinas de casas de barrios opuestos, torres... Y esto le hace a uno vivir, convivir con toda la población en cualquier momento; se siente uno arropado por la ciudad, se finge uno como centro de todos los edificios y de toda la vida. En París, al contrario: no se divisa ni el fin de la calle; las casas lo aprisionan a uno y se piensa que más allá de lo que se divisa hay otras calles y otros barrios y luego otros y otros que no toman parte en nuestra vida. Se considera uno un ser sin importancia, uno de tantos miles y miles (Ortega y Gasset, 1991: 99-101).

La conclusión inmediata que extraemos de estas palabras es que el joven Ortega, en su breve parada en París de camino a Leizpig, no había hecho otra cosa que dedicarse a la flânerie hasta reventar. Una experiencia que no parecía haberle agradado: la gran capital francesa, con su inmenso despliegue de calles y sus multitudes, acabó por abrumar al filósofo, nada amigo ya por entonces de la disolución individual a la que condenaban las grandes urbes.

Ortega volvió en 1911 a París, donde estaba su amigo Ignacio Zuloaga. Con ocasión de su encuentro con el pintor, 
Ortega publicó en La Prensa el artículo «Una visita a Zuloaga», aflorando de nuevo la sombra de Baudelaire:

París es todo luz. ¿No es esto fatal? Porque yo quisiera ver algo, llevarme al hondón de España una poderosa intuición. Pero no habiendo sino luz en París no hay nada que ver [...]. Se habla de originalidad a menudo y se entiende por tal yo no sé qué ingenua pretensión existente en algunos hombres de inventar algo completamente nuevo. Nada hay nuevo, nada hay viejo si no es sólo de nombre: el puente más viejo de París es el Pont Neuf. Hay, sí, unas realidades esenciales y perennes, sentidas desde los comienzos de la cultura, y en torno a ellas una variación incesante de semirrealidades ingrávidas e insignificantes, las cuales no son nuevas ni son viejas, porque son simplemente momentáneas. Hombre verdaderamente original es quien, a través de esas reverberaciones superficiales, mete bien hondo la mirada y la mano en aquellos problemas cordiales, eternos, y los saca un momento a las miradas de las gentes (Ortega y Gasset, 2004a: 529-531).

Ortega parecía decepcionado; en París, allá por 1911, no había nada que ver. $\mathrm{Ni}$ «lo nuevo» ni «lo viejo» se revelaban por ninguna de sus calles; de estas categorías sólo quedaba la monumental paradoja que encarnaba el Pont Neuf. Aunque Ortega desplegaba estas cuestiones con el fin último de elogiar a Zuloaga -lo único digno de ver en París-, en sus palabras se intuye algo más que una decepción ante la capital francesa: en ellas se ve a Baudelaire resplandeciendo con todo su poder. El hombre original del que habla Ortega, aquel que es capaz de extraer de las gentes las cuestiones eternas que quedan camufladas bajo las reverberaciones momentáneas... ¿no es acaso el pintor de la vida moderna? Y más aún: ¿qué es la constatación de la paradoja encarnada en el Pont Neuf sino la materialización simultánea de «lo viejo» y de «lo nuevo»? ¿No sería el Pont Neuf la verdadera visión de Ortega en París, el indicio de la existencia de una solución para ese problema que señaló en la primera lección de ¿Qué es filosofía? y que no es otro que el problema de fondo, el motor, del pintor moderno descrito por Baudelaire: la unión de lo temporal y de lo eterno? ${ }^{5}$

En su artículo de 1915 «La guerra, los pueblos, los dioses», Ortega volvió a mostrar su conocimiento expreso de Baudelaire al describir el presente como un nuevo con- glomerado de mitos que encontraba en la ciudad el lugar sacrosanto de su batalla. Afirmaba Ortega:

\begin{abstract}
Un pueblo es su mitología, y mito es todo lo que pensamos cuando no pensamos como especialistas, como médicos, como pintores, como economistas. Mitología es el aire de ideas que respiramos a toda hora; son los pensamientos espontáneos que van por las calles de las urbes como canes sin dueño; son las emociones anónimas que mueven las muchedumbres; son los prejuicios de las madres y las pardas consejas que cuentan las nodrizas; son los lugares comunes de la Prensa y de los oradores (Ortega y Gasset, 2004a: 917).
\end{abstract}

En las ciudades modernas circulaban, de forma anónima y entre las multitudes, como «un aire de ideas», los nuevos mitos del presente. En tanto «canes sin dueño», estos mitos se presentaban ante los ojos del hombre moderno como el gran jeroglífico que descifrar en su búsqueda de los nuevos relatos épicos con los que explicar su propio tiempo. No fue Ortega el primero en señalar que el mundo moderno desplegaba nuevos enigmas a la espera de su resolución. Fue Baudelaire quien planteó la cuestión en su célebre soneto de Las flores del mal «Correspondencias» (1857). Para Baudelaire el mundo era un bosque de símbolos que, a pesar de sus perfiles inasibles, manifestaban una profunda unidad, toda una serie de ocultas correspondencias bajo la apariencia de sus superficies (Baudelaire, 1982: 19-20). Y del mismo modo se manifestó Ortega en sus Meditaciones del Quijote: el mundo era un bosque, un lugar donde, para salir airoso descifrando el oculto sentido de las cosas, debía mantenerse la visión tanto de la profundidad como de la superficie:

Tengo yo ahora en torno mío hasta dos docenas de robles graves y de fresnos gentiles. ¿Es esto un bosque? Ciertamente que no: éstos son los árboles que veo de un bosque. El bosque verdadero se compone de los árboles que no veo. El bosque es una naturaleza invisible -por eso en todos los idiomas conserva su nombre un halo de misterio- [...].

Desde uno cualquiera de sus lugares es, en rigor, el bosque una posibilidad [...]. El bosque es una suma de posibles actos nuestros, que al realizarse, perderían su valor genuino. Lo que del bosque se halla ante nosotros de una 
manera inmediata es sólo pretexto para que lo demás se halle oculto y distante (Ortega y Gasset, 2004a: 764-765).

Ortega coincidía, por tanto, en la experiencia primordial de Baudelaire. En la ciudad se producía la misma experiencia que cuando se está inmerso en la naturaleza: no sólo el mundo se revelaba como un bosque de símbolos que descifrar sino que, principalmente, en ella el sujeto se veía sacudido por un doble fenómeno de concentración y disolución, ese fenómeno que Baudelaire dejó apuntado en Mi corazón al desnudo: «De la evaporación y de la centralización del yo. Todo radica en eso» (Baudelaire, 1983: 38). Ahí residía la «religiosa embriaguez de las grandes ciudades» de la que también habló Baudelaire: el panteísmo donde «Yo soy todos» y «Todos, soy yo» (Baudelaire 1983: 17). Pues, en el bosque, en la ciudad, a pesar de estar dentro de su estructura y con todos sus elementos desplegados alrededor del centro virtual ocupado, la mirada, la percepción de la realidad debe también superar su posición y disolverse en una aprehensión más profunda del conjunto. Tal y como lo formuló Ortega, el sujeto moderno debía aprender a desplazarse de la concentración del yo que es la perspectiva individual a la disolución del mismo yo que se produce con la reabsorción de las circunstancias:

Y esto es la profundidad de algo: lo que hay en ello de reflejo de lo demás, de alusión a lo demás. El reflejo es la forma más sensible de existencia virtual de una cosa en otra. El "sentido» de una cosa es la forma suprema de su coexistencia con las demás, es su dimensión de profundidad. No, no me basta con tener la materialidad de una cosa, necesito, además, conocer «el sentido» que tiene, es decir, la sombra mística que sobre ella vierte el resto del universo.

Preguntémonos por el sentido de las cosas, o lo que es lo mismo, hagamos de cada una el centro virtual del mundo (Ortega y Gasset, 2004a: 782).

Este deseo de preguntarse por el sentido de las cosas y de convertirlas en el centro virtual del mundo no mostraba otra cosa que la intención de interrogarse también por el hombre y por su lugar en los tiempos modernos. Y, para encontrar la solución, Ortega, como veremos, volvió a recurrir a Baudelaire.

A partir de 1926, y en no pocas ocasiones, Ortega comenzó a referirse de forma constante a uno de los lamentos que el poeta francés había vertido en sus Pequeños poemas en prosa, concretamente en el titulado «En cualquier parte fuera del mundo». Decía Baudelaire:

Esta vida es un hospital en el que cada enfermo está poseído por el deseo de cambiar de cama. Éste quisiera sufrir frente a la estufa, y aquel que curaría junto a la ventana.

Creo que yo estaría siempre bien donde no estoy, y esta idea de mudanza es una de las que constantemente discuto con mi alma [...].

Mi alma finalmente explota y sabiamente me grita: «iEn cualquier sitio, en cualquier sitio, siempre y cuando sea fuera de este mundo!» (Baudelaire, 1986: 134-135).

Serían los gritos finales los que marcaron profundamente a Ortega: « En cualquier sitio, en cualquier sitio, siempre y cuando sea fuera de este mundo!». Para Ortega este lamento expresaba a la perfección el estado de mudanza en el que se encontraba el hombre moderno, su inquietud por no hallar orden ni concierto en un mundo sometido al cambio incesante. Es por esta razón por lo que Ortega empleó los gritos finales de Baudelaire como ilustración de un amplio repertorio de temas: el éxtasis amoroso, la «realidad radical», el conocimiento, el hombre y la gente ${ }^{6}$, etc. Pero fue en dos escritos donde esta formulación de Baudelaire, que tan bien parecía encajar con todos los aspectos del pensamiento orteguiano, encontró su expresión más reveladora: «Ensimismamiento y alteración» (1939) e «Idea del teatro» (1946).

En «Ensimismamiento y alteración» Ortega empleó las palabras del poeta francés con un sentido mayor que en otras ocasiones:

Noten ustedes que esta maravillosa facultad que el hombre tiene de libertarse transitoriamente de ser esclavizado por las cosas implica dos poderes muy distintos: uno, el poder desatender más o menos tiempo el mundo en torno sin riesgo fatal: otro, el tener dónde meterse, dónde estar, cuando se ha salido virtualmente del mundo. Baudelaire expresa esta última facultad con romántico y amanerado dandismo, cuando al preguntarle alguien dónde preferiría vivir, él respondió: «En cualquier parte, con tal que sea fuera del mundo!» Pero el mundo es la total exterioridad, el absoluto fuera que no consiente ningún fuera más allá de él. El único fuera de ese fuera 
que cabe, es precisamente, un dentro, un intus, la intimidad del hombre, su sí mismo que está constituido principalmente por ideas (Ortega y Gasset, 2006: 536).

El grito de Baudelaire era, a los ojos de Ortega, la gran paradoja nacida con la modernidad. La imposibilidad del hombre por encontrar su lugar en el mundo se producía por la expulsión, por el «absoluto fuera» que había impuesto al sujeto el espacio abarrotado y en continuo movimiento de las ciudades; por ese estadio en el que, según Ortega, «el hombre se siente perdido, náufrago en las cosas»: la alteración (2006: 539). Y, en consecuencia, «el único fuera de ese fuera» que le restaba al hombre era el dentro, su intimidad: el lugar de retiro donde tratar de «formarse ideas sobre las cosas y su posible dominación» que Ortega denominó «ensimismamiento» (2006: 539). Pero, como sabe cualquier lector atento tanto de Baudelaire como de Ortega y Gasset, la solución no podría radicar en la evasión del fuera con un mero repliegue hacia dentro. Tal y como señaló Ortega en este ensayo y como veremos más adelante, otro punto debía completar los dos estadios previos de alteración y ensimismamiento. La disolución en el exterior y la concentración en el interior debían poder coexistir gracias al poder de algún mecanismo conciliador.

Fue en «ldea del teatro» donde Ortega desveló dónde se encontraba la clave para la integración de este problema:

La vida es un omnímodo hacer. Y todo ello en lucha con las circunstancias y porque está prisionero en un mundo que no ha podido escoger. Este carácter que tiene cuanto nos rodea de sernos impuesto, queramos o no, es lo que llamamos «realidad» $[\ldots]$.

Por eso cuando alguien le preguntaba a Baudelaire dónde prefería vivir, con un gesto de dandismo displicente que era, según es sabido, su religión, respondió: «iEn cualquier parte, ah en cualquier parte, con tal que sea fuera del mundo!»

Con ello, daba a entender Baudelaire lo imposible. El Destino tiene al hombre irremediablemente encadenado a la realidad y en lucha sin tregua con ella. Es imposible la evasión. El tener que hacerse su vida y decidir en cada instante, con su exclusiva responsabilidad, lo que va a hacer, es como si tuviese que sostenerla a pulso. Por eso la vida está llena de pesadumbre. A una criatura, así, el Hombre, cuya condición es tarea, esfuerzo, seriedad, responsabilidad, fatiga y pesa- dumbre, le es inexcusablemente necesario algún descanso. ¿Descanso de qué? ¡Ah, claro está! -de qué va a ser? De vivir o, lo que es igual, de «estar en la realidad», náufrago en ella.

Esto es lo que irónicamente quería decir Baudelaire: que el hombre necesita de cuando en cuando evadirse del mundo de la realidad, que necesita escapar. Hemos dicho que esto es imposible en sentido absoluto. Pero ¿no será en algún sentido menos absoluto posible? Mas para irse en vida de este mundo, sería menester que hubiese otro. $Y$ si ese mundo es otra realidad, por muy otra que sea, será realidad, contorno impuesto, circunstancia premiosa. Para que haya otro mundo a que mereciera la pena irse, sería preciso, ante todo, que ese otro mundo no fuese real, que fuese un mundo irreal. Entonces estar en él, ser en él, equivaldría a convertirse uno mismo en irrealidad. Esto sería efectivamente suspender la vida, dejar un rato de vivir, descansar del peso de la existencia, sentirse aéreo, etéreo, ingrávido, invulnerable, irresponsable, in-existente (Ortega y Gasset, 2009: 846-847).

De modo que el único modo de superar el naufragio que la realidad imponía al hombre moderno se encontraba en la evasión hacia otro mundo donde la vida se suspendiese temporalmente y la existencia se tornase aérea, etérea, ingrávida, invulnerable. Ese otro mundo, ya lo intuimos, es el mundo de la creación artística. ¿No es el arte el punto de confluencia de todos los problemas a los que se venía enfrentando Ortega, a saber: profundidad y superficie, lo temporal hecho eterno, una dialéctica entre el hombre y la gente, el proceso resultante del paso por la alteración y el ensimismamiento, un mundo fuera del mundo pero en relación indisoluble con él?

Tal y como mostró en Ideas y creencias (1940), el hombre debía enfrentarse a la realidad exterior y sus enigmas mediante la imaginación. Gracias a esta facultad -la misma que ensalzó Baudelaire en Delacroix en su Salón de 1859 (Baudelaire, 1999: 248)-, el hombre conciliaba ensimismamiento y alteración, concentración y disolución.

Pues resulta que ante la auténtica realidad, que es enigmática $y$, por tanto, terrible [...], el hombre reacciona segregando en la intimidad de sí mismo un mundo imaginario. Es decir, que por lo pronto se retira de la realidad, claro que imaginariamente, y se va a vivir a su mundo interior [...]. Lo que llamamos nuestra intimidad no es sino nuestro imaginario mundo, el 
mundo de nuestras ideas. Ese movimiento merced al cual desatendemos la realidad unos momentos para atender a nuestras ideas es lo específico del hombre y se llama «ensimismarse». De ese ensimismamiento sale luego el hombre para volver a la realidad, pero ahora mirándola, como con un instrumento óptico, desde su mundo interior, desde sus ideas, algunas de las cuales se consolidaron en creencias. $Y$ esto es lo sorprendente que antes anunciaba: que el hombre se encuentra existiendo por partida doble, situado a la vez en la realidad enigmática y en el claro mundo de las ideas que se le han ocurrido. Esta segunda existencia es, por lo mismo, «imaginaria», pero nótese que el tener una existencia imaginaria pertenece como tal a su absoluta realidad (Ortega y Gasset, 2006: 677-678).

Al generar nuevos mundos interiores, mundos imaginarios, el hombre encontraba el puente con el que aunar exterioridad e interioridad y, en consecuencia, la clave con la que convertir el mundo en un lugar articulado y pleno de sentido. Ortega nos señala que entre estos mundos se encuentran «el mundo matemático, el mundo físico, el mundo religioso, moral, político y poético» (2006: 677). Pero es el mundo poético -entendiendo por poético poiesis, esto es, todos los ámbitos de la creación- el ámbito más destacado de todos ellos.

El hecho de que la estética nacida con los tiempos modernos se basaba en esta dialéctica entre la concentración y la disolución fue visto muy claramente por Ortega. Es en su artículo «Musicalia» (1921) donde esta cuestión quedó planteada de forma definitiva:

A veces se abre en el fondo de nuestra intimidad un manantial de deleitables recuerdos. Entonces parece que nos cerramos al mundo exterior, y recogiéndonos sobre nosotros mismos, permanecemos atentos al íntimo hontanar, degustando ensimismados el trémulo brotar de las fragantes reminiscencias. Esta actitud es la concentración hacia adentro. Si de pronto suenan unos pistoletazos en la calle, salimos de la inmersión en nosotros mismos, emergemos al mundo exterior, y asomándonos al balcón, ponemos, como suele decirse, los cinco sentidos, toda la atención, en el hecho que acontece en la rúa. Ésta es la concentración hacia fuera.

Pues bien; cuando oímos la romanza en fa, de Beethoven, u otra música típicamente romántica, solemos gozar de ella concentrados hacia dentro. Vueltos, por decirlo así, de es- paldas a lo que acontece allá en el violín, atendemos al flujo de emociones que suscita en nosotros. No nos interesa la música por sí misma, sino su repercusión mecánica en nosotros, la irisada polvareda sentimental que el son pasajero levanta en nuestro talón fugitivo. En cierto modo, pues, gozamos, no de la música, sino de nosotros mismos. En tal linaje musical, viene a ser la música mero pretexto, resorte, choque que pone en emanación los fluidos vahos de nuestras emociones. Los valores estéticos se prenden, por tanto, más bien en éstas que en la línea musical objetiva, en el tropel de sones que transita sobre el puente del rubio violín. Yo diría que oímos la romanza en fa, pero escuchamos el íntimo canto nuestro.

La música de Debussy o de Strawinsky nos invita a una actitud contraria. En vez de atender al eco sentimental de ella en nosotros, ponemos el oído y toda nuestra fijeza en los sonidos mismos, en el suceso encantador que se está realmente verificando allá en la orquesta. Vamos recogiendo una sonoridad tras otra, paladeándola, apreciando su color, y hasta cabría decir que su forma. Esta música es algo externo a nosotros: es un objeto distante, perfectamente localizado fuera de nuestro yo y ante el cual nos sentimos puros contempladores. Gozamos la nueva música en concentración hacia fuera. Es ella la que nos interesa, no su resonancia en nosotros (Ortega y Gasset, 2004b: 372-373).

El arte, tal y como lo planteó Ortega y Gasset, consistía en una especie de liberación por la que el sujeto lograba salir de sí mismo y acceder a un afuera sin perder su propio dentro -la concentración de donde nació todo este proceso de transfiguración-. Así lo expuso Ortega en su Ensayo de estética a manera de prólogo (1914):

El arte es esencialmente IRREALIZACIÓN [...]. Es el arte doblemente irreal: primero, porque no es real, porque es otra cosa distinta de lo real; segundo, porque esa cosa distinta y nueva que es el objeto estético, lleva dentro de sí como uno de sus elementos la trituración de la realidad. Como un segundo plano sólo es posible detrás de un primer plano, el territorio de la belleza comienza sólo en los confines del mundo real (Ortega y Gasset, 2004a: 678).

Mediante el arte nuevo, el hombre moderno lograba tender un puente entre la temporalidad de su presente -entre la fugacidad de las cosas y la esclavitud de su yo con 
respecto a ellas- y los valores eternos -la liberación del yo en la comunión universal-. El pintor de la vida moderna descrito por Baudelaire no tuvo otra misión: atrapar la eternidad en los fenómenos del mundo, «extraer de la moda lo que ésta puede contener de poético en lo histórico [...], obtener lo eterno en lo transitorio» (Baudelaire, 2003: 91).

\section{Notas}

1 Tanto en las reflexiones de 1922 como en su ensayo de 1925, Ortega introduce a Baudelaire como ilustración de la actitud combativa que las nuevas generaciones de creadores establecen contra sus predecesoras, contra la tradición. Así, en el «Brindis en un banquete en su honor en 'Pombo'», el filósofo madrileño se refería al poeta francés en este sentido, a saber, en términos de "combate intelectual» y en los mismos términos vuelve Ortega a referirse a Baudelaire en La deshumanización del arte: véase Ortega y Gasset, 2005a: 407 y 871, respectivamente.

2 Fue en el artículo «Baudelaire», publicado en el número del 31 de enero de 1904 de Alma española, cuando Azorín declaró al poeta francés el «padre de la poesía decadente moderna» (Azorín, 1904: 3). Respecto a la influencia baudelairiana en los conceptos de tiempo y de Historia en Azorín, véase González del Valle, 2007: 150-154.

3 «Sin embargo, el mismo Baudelaire, el primero en usar la palabra 'modernidad' en su actual acepción para reivindicar con ella el particular valor de la estética de su tiempo, guardaba en mente algo de su antiguo sentido. Aunque la haga sonar a consigna, no deja de recordar al lector que la modernidad 'nunca es sino la mitad del arte'. 'La otra mitad -dice- es lo eterno y lo inmutable'. La postulación de lo actual, de lo efímero, el gusto por lo transitorio y fugaz, la necesidad de lo inaudito y lo nunca visto, todos esos rasgos de la vida moderna siempre deben venir, según él, acompañados, pero a la vez mesurados, moderados, ponderados y justificados, por una postulación similar pero inversa de lo inmóvil y siempre presente. El 'sueño de piedra' al que Baudelaire asemeja lo Bello, su odio al movimiento que 'descoloca las líneas', están bien cerca en este sentido de los ensueños de Winckelmann con la Antigüedad [...]. Presa entre el fulgor maníaco de lo nuevo y la petrificación melancólica del pasado, la modernidad es siempre para Baudelaire desgarro, vacilación, postulación simultánea, equilibrio entre apropiación y desposesión, gozo y duelo» (Clair, 1998: 24-25).

4 El magnífico libro de Paul Lidsky, Los escritores contra la Comuna, pone de relieve, sin miramientos, cómo las grandes figuras literarias del siglo XIX francés (Flaubert, Mallarmé, los hermanos Goncourt, Leconte de Lisle, Zola...) desplegaron su lado más reaccionario ante el levantamiento de la Comuna de París en 1871. En concreto, Baudelaire fue uno de los más explícitos y despiadados al respecto, manifestando su complacencia ante la paliza de un policía a un republicano (Lidsky, 1971: 22-23).

5 «Es inútil que intentemos violentar nuestra sensibilidad actual que se resiste a prescindir de ambas dimensiones: la temporal y la eterna» (Ortega y Gasset, 2008: 243).

6 En «Amor en Stendhal» (1926) Ortega empleó por primera vez este lamento (Ortega y Gasset, 2006: 491) y pocos años después, en 1930, «Sobre la realidad radical» acogió de nuevo el lamento baudelairiano (Ortega y Gasset, 2008: 380). En el curso «¿Qué es el conocimiento?» (1931) Ortega volvió a emplear la misma referencia (Ortega y Gasset, 2005b: 573) y en 1935 el filósofo retomó las mismas ideas para sus reflexiones sobre El hombre y la gente (Ortega y Gasset, 2009: 206).

\section{Bibliografía}

AZORÍN (1904), «Baudelaire», Alma española, Madrid, año II, n. 13, 31 de enero de 1904.

BAUDELAIRE, Charles (1982), Las flores del mal, Orbis, Madrid.

- (1983), Mi corazón al desnudo y otros papeles íntimos, Visor, Madrid.

- (1986), Pequeños poemas en prosa. Los paraísos artificiales, Cátedra, Madrid.

- (1999), Salones y otros escritos sobre arte, La balsa de la Medusa, Madrid.

- (2003), El pintor de la vida moderna, Colegio Oficial de Aparejadores y Arquitectos Técnicos en la Región de Murcia, Murcia.

CLAIR, Jean (1998), La responsabilidad del artista. Las vanguardias, entre el terror y la razón, La balsa de la Medusa, Madrid.

COMPAGNON, Antoine (2007), Los antimodernos, Acantilado, Barcelona.

GONZÁLEZ DEL VALLE, Luis T. (2007), La canonización del diablo. Baudelaire y la estética moderna en España, Editorial Verbum, Madrid. HAMBROOCK, Glyn (1995a), The influence of Charles Baudelaire in Spanish Modernismo, Universidad de Notthingham (Tesis Doctoral).

- (1995b), «Juan Ramón Jiménez, Reader of Baudelaire», Tesserae, vol. 1, n. 3, 1995, pp. 367-388.

- (2012), «Translations of Baudelaire in Spain 1880-1910», The Modern Language Review, vol. 17, n. ${ }^{\circ}$, enero de 2012 , pp. $20-38$.

LIDSKY, Paul (1971), Los escritores contra la Comuna, Siglo XXI, México.

ORTEGA Y GASSET, José (1991), Cartas de un joven español (1891-1908), Ediciones El Arquero, Madrid.

- (2004a), Obras completas. Tomo 1-1902/1916, Fundación Ortega y Gasset-Taurus, Madrid.

- (2004b), Obras completas. Tomo II-1916, Fundación Ortega y Gasset-Taurus, Madrid. 
ORTEGA Y GASSET, José (2005a), Obras completas. Tomo III-1917/1925, Fundación Ortega y Gasset-Taurus, Madrid.

- (2005b), Obras completas. Tomo IV-1926/1931, Fundación Ortega y Gasset-Taurus, Madrid.

- (2006), Obras completas. Tomo V-1932/1940, Fundación Ortega y Gasset-Taurus, Madrid.

- (2008), Obras completas. Tomo VIII-1926/1932. Obra póstuma, Fundación Ortega y Gasset-Taurus, Madrid.

- (2009), Obras completas. Tomo IX-1933-1948. Obra póstuma, Fundación Ortega y Gasset-Taurus, Madrid.

VALLE-INCLÁN, Ramón María del (1916), La lámpara maravillosa, Sociedad General Española de Librería, Madrid. 